\title{
Design thinking mindset to enhance education 4.0 competitiveness in Malaysia
}

\author{
Suhaila Che Noh, Abdul Malek Abdul Karim
}

School of Education and Modern Languages, Universiti Utara Malaysia, Malaysia

\begin{tabular}{l} 
Article Info \\
\hline Article history: \\
Received Sep 3, 2020 \\
Revised Mar 18, 2021 \\
Accepted Apr 12, 2021 \\
\hline
\end{tabular}

\section{Keywords:}

Creative and innovative thinking

Design thinking

Design thinking mindset education 4.0

Industry revolution 4.0

\begin{abstract}
Education 4.0 will be the next aspect of the curriculum since programming has been taught from the primary school level. Training 4.0 requires teachers to equip students with not only the knowledge and information but also encourage students to be able to process information, develop creative thinking, and acquire problem-solving skills. However, the competency of teachers to encourage creative thinking and problem-solving skills is still questionable. The purpose of this concept paper is to provide an understanding of the conceptual framework for enhancing the teachers' competency to enhance creativity and innovation in fulfilling the desire of education 4.0. design thinking is an innovative method that places people right at the center of problem solving. It discusses the variables that may affect the quality of teachers in education 4.0 and presents a literature review of approaches that can contribute to the creation of effective teaching methods to develop successful students and satisfy the demands of the workforce for industrial revolution 4.0. It is found that teachers need to be competent to build students' skills in meeting a competitive and innovative workforce in the wake of the industrial revolution 4.0. There are seven dimensions in the design thinking mindset that teachers need to understand to meet the 4.0 education requirements.
\end{abstract}

This is an open access article under the CC BY-SA license.

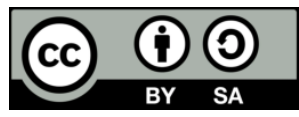

\section{Corresponding Author:}

Suhaila Che Noh

School of Education

Universiti Utara Malaysia

06010 Bukit Kayu Hitam, Kedah, Malaysia

Email: suhailachenoh.kmp@gmail.com

\section{INTRODUCTION}

Education is changing due to the rapid development in information and communications technology and technology advancement in the era of Industrial Revolution 4.0 (IR 4.0). IR 4.0 involves technology that changes the way humans think, the world's economic system, and social roles [1]. The development and advancement in IR 4.0 are not only changing the economic, social, and political systems but are also affecting the education system [2]. The 21st-century learning changes the students' learning landscape from teacher-centred to a more learner-centred approach. It focuses on the use of technology for information searching and act as a catalyst for inquiry-based learning [3]. This is in line with the Malaysia Education Blueprint 2013-2025 that aims to prepare individuals to enter the workforce in accordance with the employment needs [4], [5]. To ensure that these demands are met, teachers should no longer be dependent on the traditional method to carry out teaching activities in the classroom.

As technology permeates into all aspects of life, it is pertinent that students understand how to best use technology to improve the quality of life. Teachers must therefore, equip themselves with the knowledge 
and the necessary teaching skills so that they could prepare students not only for careers that increasingly require the use of new technologies, but also to understand the impact of technology on society [6], [7]. Based on the literature, a few studies were identified to focus on teaching or developing 21 st-century skills and competencies [8]. Teachers today should be attentive to the development and demands in the field of technology in education 4.0. Students cannot develop the skills if the teachers do not have sufficient knowledge in imparting the skills to them. It is important for students to master the skills that cannot be replaced with technology [9]. Hence, teachers need to change their teaching methods and approaches according to the 21 st-century teaching and learning framework that adapted to market needs [10], [11]. Teachers must build their own competencies so that they could develop students' creative and innovative skills in technology [12]. This statement is supported by Dillon, et al. [13] who emphasized that technology will continue to change the teaching and learning method in today's world and in the future. Teachers and educators should train students with the 21 st century skills in meeting the demands for IR 4.0.

Among the approaches that has been found to be successful in creating students who are prepared for IR 4.0 is design thinking (DT). DT is a way of learning that acts as a cycle and a series of methods in developing creativity and innovation. Both aspects have important consequences for industrial enhancement [14]. DT guides and shapes behaviours as a process and a toolkit when facing uncertainty and problemsolving skills. DT provides a robust and adaptive approach for directing teachers and influence their creativity in dealing with practical problems [15]. To ensure that teachers can practice DT, they must be conditioned to have a DT Mindset. DT is more commonly accepted in the industry or in product and service design, but currently has gained a growing interest in education [16]. However, the growing complexity and dependency on technology needs teachers conserve with the seven-dimensional elements of DT in the teaching and learning technology.

While there is a lot of debate, education evidence on this topic is still weak [17]. Therefore, teachers need to change their teaching methods and approach. Thus, it is important for students nowadays to master the skills that cannot be replaced with technology [9]. This is where there is a need to develop 21st-century teaching and learning skills in today's education. However, students cannot develop the skills if the teachers do not have sufficient knowledge in training the skills to the students. The 21 st-century teaching and learning method is important in the effort towards building teachers' competencies in teaching students to develop a good foundation in technology [12].

Based on this explanation, the idea is to inspire students to be creative and innovative. Therefore, one thing that needs to be considered is the competency of teachers who need to adapt with the competitiveness of education 4.0. This paper aims to present a conceptual framework for improving teacher's creativity and innovation skills through the design thinking mindset, in the effort to enhance education 4.0 competitiveness in Malaysia.

\section{RESEARCH METHOD}

The researcher used data analysis for a systematic study of evaluations, reviews and findings in peer-reviewed articles, reports, and dissertations. Digital repositories such as Scopus, Springer, JSTOR and Google Scholar were searched comprehensively using the terms check and research on learning, creative and innovative thinking, design thinking, design thinking mindset, Industry Revolution 4.0, and Education 4.0. Based on the search, 50 articles from 2010 to 2020 were obtained and systematically analyzed. The articles were carefully reviewed in order to better understand the principles of concept, idea and contribution and how they are used in educational studies [18], particularly in the context of Malaysia. Authenticity, credibility, and specificity were the key characteristics of the review's interpretive document analysis [19], [20]. Many articles were read in order to truly understand their conceptual perspectives. Figure 1 presents the flowchart of reviewed articles selection processes that contribute a conceptual framework for new knowledge to validate the statements, theories, and concepts of scholars in DT, DT mindset, IR 4.0 and education 4.0 towards creative and innovative thinking. Ultimately, a detailed debate on the principles and how they are used to determine the academic success of learners was discussed. 


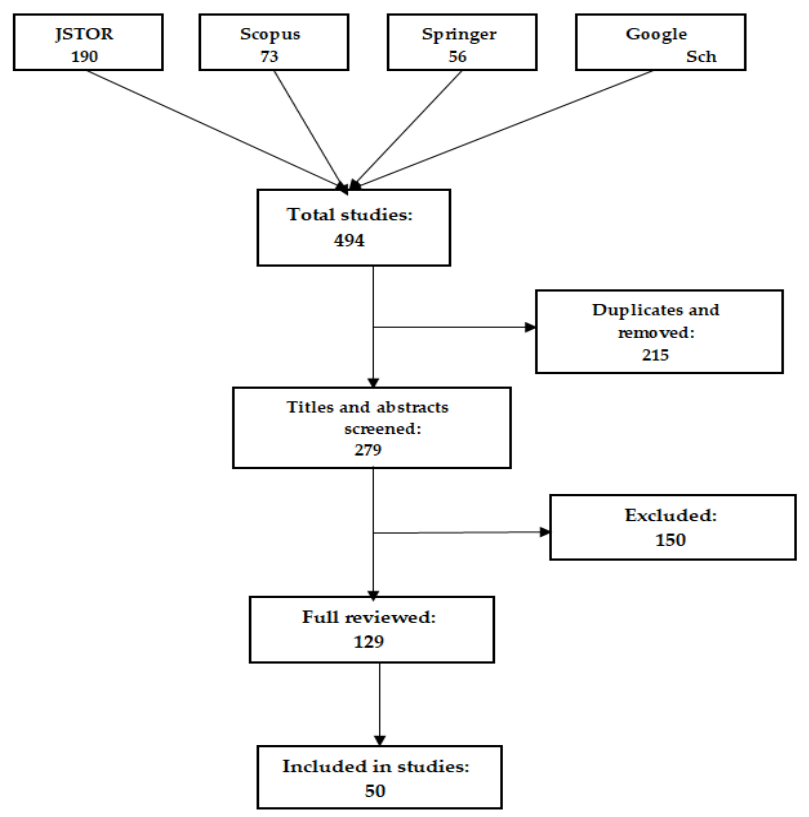

Figure 1. Flowchart of reviewed articles selection process

\section{RESULTS AND DISCUSSION}

\subsection{Design thinking in education}

The field of education is continuously changing with new methods to increase students' learning. Along with that is to equip the students with skills that would enable them to face the demands of the 21 st century skills and IR 4.0. One approach that promises to fulfil the above needs is design thinking (DT). This study examines issues and challenges in adapting DT in IR 4.0 teaching. There is a lack of empirical inquiries on the DT application and implementation processes in the educational context in Malaysia. The second wave in the Malaysian Education 2013-2025 blueprint aims to create a problem-solving thinking development model that supports epistemological shift through DT thinking in a high-quality learning environment (Ministry of Education Malaysia, 2018). DT application in the curriculum offers vast potentials to enrich better learning in various fields through the DT Mindset integration.

Design thinking (DT) is generally defined as a creative and analytical process for an individual in giving an opportunity to create, to try and produce prototype models, and to produce feedbacks and change a design [21]. According to Henriksen, Richardson, and Mehta [17], DT is a thinking framework to solve complex problems in this "conceptual age" where creativity and innovation has become the main contributors to the increase of productivity in various sectors. Koh, et al. [22], define DT as the stimulation to analytic and intuitive thinking. Various definitions show that DT needs different ways of approach in solving problems, which involves a systematic process to achieve the desired output. Understanding and fulfilling users' needs by ways of thinking and different innovations, are the gains from the output of DT. Based on this definition, innovations can happen in multiple forms such as service, products, behaviours, and organizational culture fields through DT practice. Overall, DT can be regarded as an intelligent process and organizations can benefit from using DT to excel in a competitive environment [23], [24].

In the field of education, the a characteristic of design thinking and the importance should be discussed in promoting problem-solving skills to the students in the 21st century [25]. DT enables students to develop skills like collaboration, empathy, creativity, and problem-solving, as well as helping teachers to create efficiency in learning by applying the integration of curriculum to fulfil future learning by fulfilling high technological needs [26]. Global Initiative Sharing for 21st Century Skills or P21 has described a new teaching style that has emerged as a way for the students to adapt to new needs. Various studies at the global levels [27]-[30] had implemented DT as the strategy in applying empathy, problem-solving, prototype processing and multidisciplinary collaborative approach in teaching creativity, and building creative confidence and innovative minds. Thus, Figure 2 represents the DT application framework in education by Lor [29] which shows the relationship between three dimensions and four themes. The gist of the idea is that a successful application of DT in education needs systematic programs and integrated informing curriculum, teaching approach usage, and support resources for teachers' training. Teachers' involvement in DT has this potential.

Int J Eval \& Res Educ, Vol. 10, No. 2, June 2021: 494 - 501 


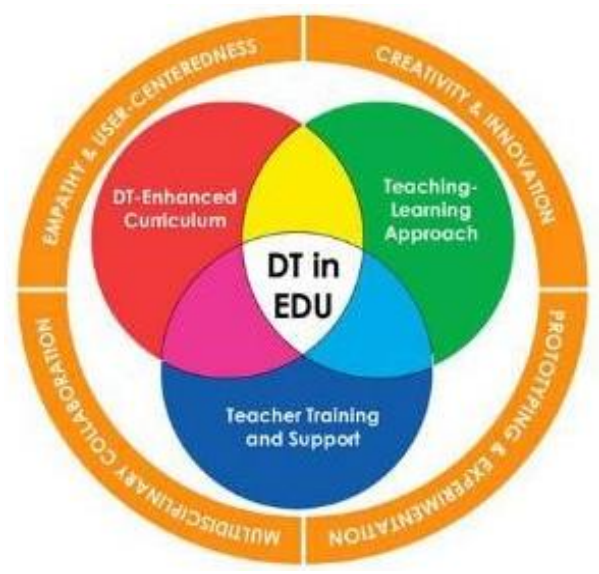

Figure 2. DT application framework in education field sources [29]

Brown [31] indicates that design thinking is a concept that involves the imagination, vision, and strategies of a creator. This meets the concerns of end-users to establish a technologically feasible and successful solution. In addition, Serrat [32] also states why concept analysis is a non-linear technique to look at to give insights into the mechanism to cope with unforeseen issues. Such questions are what most product theorists found as false problems or problems, which remain unsolved or can only be overcome through solutions via multidisciplinary approaches.

\subsection{Design thinking mindset in education 4.0}

The concept of thinking, as an increasingly common approach to creativity, involves a certain type of mindset. People who want to innovate and create better experiences, products and services for their users or customers may benefit from the application of certain attitudes that can enhance their thinking and creativity. Therefore, DT Mindset focusing on modifying, altering, or enhancing the mentalities of students, or even teachers, can build an intricate concept thought mindset in the classroom. In the context of teaching and learning, DT Mindset is based on Cognitive Psychology that provides guidance to achieve learning objectives through teaching activities and encourages thinking culture in Education 4.0 [33]. The teaching process in IR 4.0 demands students to develop creativity and innovation through computing skills and to build a skill set that balances the expert workers in the future [4].

Throughout the domain of DT, the process of approaching the integrated problems in the education curriculum is to incorporate technology into pedagogy in order to improve the professionalism of teachers [34]. However, teachers are aware that the importance and values of certain types of thinking are different attributes that will help students in building creativity and innovation. A teaching approach through creativity and innovation building is a global initiative towards the 21 st-century skills building which focuses the effort in providing skills for students' careers. The initiative from Partnership for 21st Century Skills (P21) has played active and important roles in guiding education policy by building the 21 st century skills framework. Through this initiative, 21st-century skills are integrated through the main subjects such as English, Mathematics, Computer Science, Geography, Social Studies, and Art [22].

Driven by the effort to incorporate 21st century learning capabilities, DT Mindset is required to be integrated into the curriculum. Brown [31] and Carroll, et al. [35] explain that DT Mindset is an approach for students to focus on developing creative confidence and also facing challenges in building creativity by developing empathy, encouraging a tendency to action, encouraging idea building, developing metacognitive awareness and cultivating creative problem-solving. Thus, a study by Lor [29] has divided DT Mindset, into seven dimensions, namely empathy, human-centredness, process awareness, prototype culture, experimentation, collaboration, and optimism in building creativity and innovation in teaching. Table 1 explains the seven dimensions in DT Mindset, which are the abilities that form skills in P21. It is a formal method of problem-solving or solving practical issues creatively, with the intention of better output in the future [36].

The results of the study show that Human-centredness, Empathy, Collaboration, Optimism, Experimentalism, Culture of prototyping and Mindfulness of process are required for student's employment needs in the era of IR 4.0. The application of these seven dimensions will result in the development of creativity and innovation among students [4], [17], [37]. The conceptual framework is shown in Figure 3. 
Table 1. Seven dimensions of DT mindset in education field

\begin{tabular}{|c|c|c|}
\hline Dimension & DT Mindset in education field & Source \\
\hline 1. Human-centredness & $\begin{array}{l}\text { The philosophy of design begins with a clear understanding and } \\
\text { empathy of needs and motivates students. The aim is to encourage and } \\
\text { direct people to solve the challenges of design. }\end{array}$ & Carroll et al. [35] \\
\hline 2. Empathy & $\begin{array}{l}\text { Imagine the future in specific details from a differing point of view of } \\
\text { "initial others", approaching problems certain others would not want to } \\
\text { do. To develop empathy through a method of "need seeking," which } \\
\text { focuses on specific and tacit needs of people. }\end{array}$ & $\begin{array}{l}\text { Brown [31]; } \\
\text { Carroll et al. }\end{array}$ \\
\hline 3. Collaboration & $\begin{array}{l}\text { Combination of great minds among students to build critical thinking as } \\
\text { an attempt to increase innovation when solving problems. Collaborate } \\
\text { enthusiastically with, and with other disciplines. }\end{array}$ & Brown [31] \\
\hline 4. Optimism & $\begin{array}{l}\text { Embrace the culture confidence that all students should create } \\
\text { improvements, irrespective of how big the issue is, how fast the } \\
\text { duration it requires or how limited the budget will be. Suppose at least } \\
\text { one solution is better than current one irrespective of how complex the } \\
\text { problem is. }\end{array}$ & Brown [31] \\
\hline 5. Experimentalism & $\begin{array}{l}\text { Teachers should exercise experimentalism or study about learning that } \\
\text { forms new ideas from the failure's students did in building innovation. }\end{array}$ & $\begin{array}{l}\text { Brown [31]; } \\
\text { Carroll et al. [35] }\end{array}$ \\
\hline $\begin{array}{l}\text { 6. Culture of } \\
\text { prototyping }\end{array}$ & $\begin{array}{l}\text { The central principle of DT philosophy is to develop students' skills by } \\
\text { practice. In the invention cycle, prototype is vital. Prototype is a } \\
\text { sculpting philosophy that is intuitive and easy to build inventions. } \\
\text { Concentrate on being highly experimental, building to dissolve and } \\
\text { involving people with artefacts to generate feedback for better } \\
\text { solutions. }\end{array}$ & Carroll et al. [35] \\
\hline $\begin{array}{l}\text { 7. Mindfulness of } \\
\text { process }\end{array}$ & $\begin{array}{l}\text { Mindful of the method is a way of thought that will extended to } \\
\text { students in order to ensure that any task or project is guided by phases } \\
\text { of the design cycle and the correct estimated period in the fulfilment of } \\
\text { the assignments or their tasks. Realize where the design process and the } \\
\text { methods are in and the strategic goals have become. }\end{array}$ & Carroll et al. [35] \\
\hline
\end{tabular}

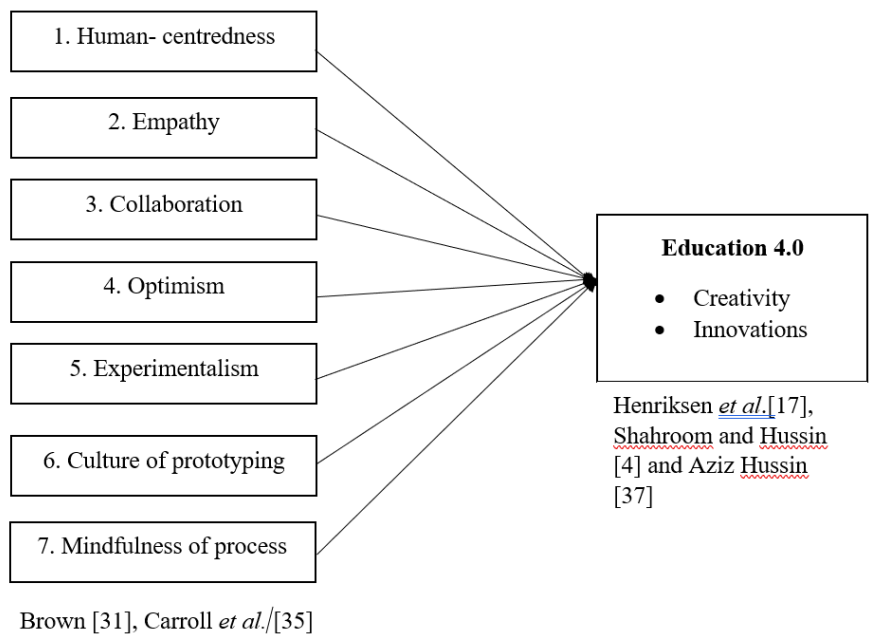

Figure 3. Conceptual framework

\subsection{Issues and challenges of DT mindset in education 4.0}

Modern schooling is distinguished by the diffusion of information by teachers. The focus is on curriculum integrity as far as the learning setting is concerned; teachers play a dominant role in teaching, where teaching styles are structured and the primary teaching goal is to gain skills [38], [39]. It is important to empower students with problem-solving skills that can retain continuity in theoretical, innovative, and creative thinking [40]. The important aim of creativity and innovative thought is to stimulate and develop the problem-solving skills of students. However, according to Malaysian Education Growth 2001-2010, most teachers still use traditional teaching strategies and not many had implemented creative and innovative thinking in the teaching and learning process [41]. Prior studies [2], [17], [42], that have noted the importance of implemented DT Mindset to apply all the elements to build creative and innovative thinking. Table 2 demonstrates the contrasts of the two instructional approaches that teachers need to apply to enhance creative and innovative thinking that dealing with DT mindset. 
Table 2. Comparison between traditional teaching and creative and innovative thinking teaching with DT mindset

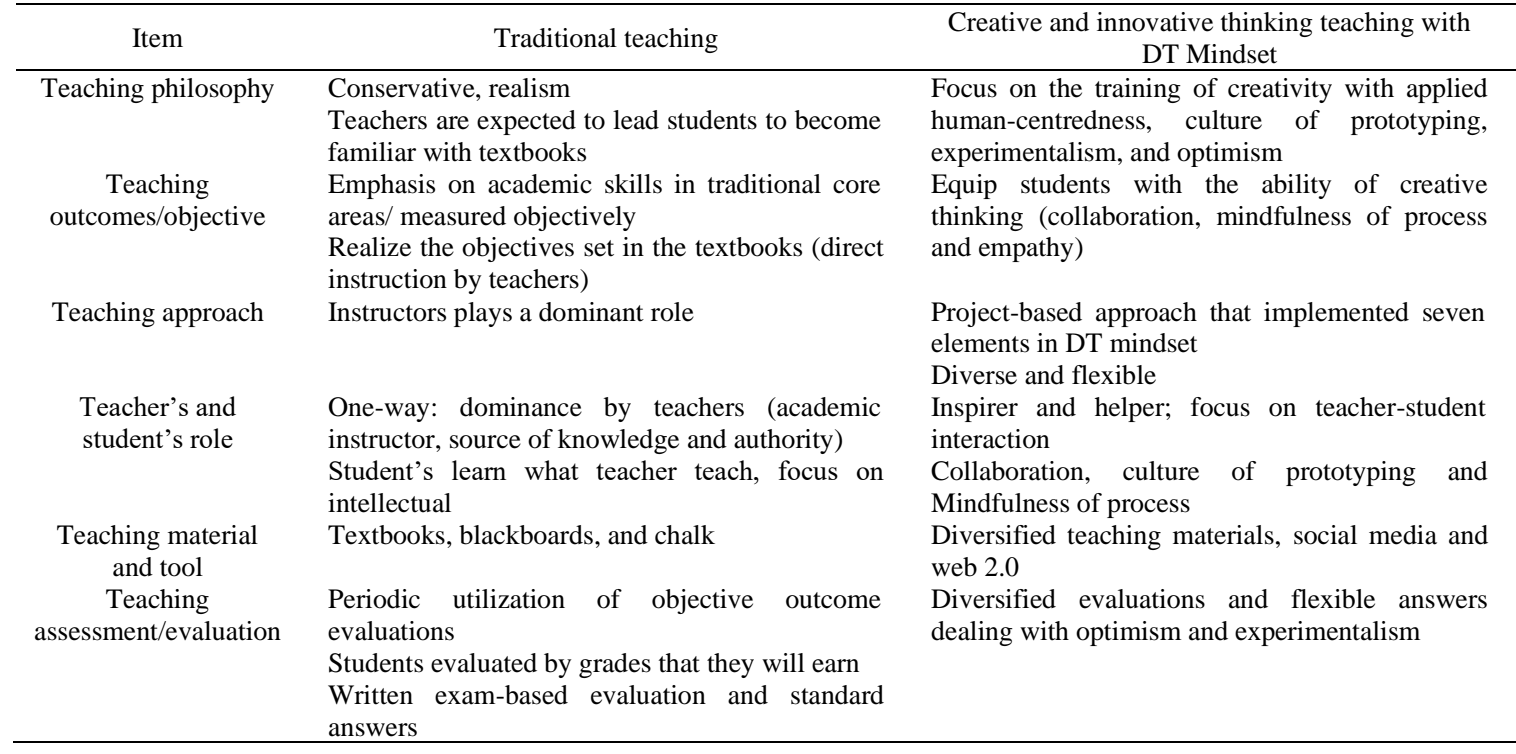

Design thinking development in Malaysia started with the initiative from the inception of Genovasi Malaysia in August 2012, with its aim to train the public and private communities using design thinking model from the Stanford d school and Hasso Plattner-Institute. Genovasi Malaysia aims to encourage and build Malaysian school students' with creative and innovative skills [43]. The emphasis on integrating creativity and innovation in teaching and learning captured the attention of the former Minister of Education who wanted creativity and innovation to be integrated in the school curriculum. This has also become the emphasis to achieve the vision of increasing the 21 st-century education system quality through the Malaysian Education Blueprint 2013-2025. The believed that DT Mindset has the potential to develop creativity and innovation has led to a demand from many parties to implement DT in the education curriculum [44]. As the key success factor lies with the teachers, it is therefore valuable to observe DT Mindset's learning constraints from the perspective of teachers. As the engine of transformation, teachers play a vital role in the success or failure of an innovation.

Creativity and innovation is an important element in building labour skills in the IR 4.0 era [45]. Hence, Education 4.0 emphasizes on building teachers' competencies so that they could develop students' creative and innovative ability, leverage on information and technology in their teaching, and to equip their students with the skills to communicate and cooperate effectively. Based on Adnan, et al. [46], creativity is the core of 21st-century thinking skills and education 4.0. Teachers should master the creative element in this education 4.0 era not only to fulfil enrichment activities in class. However, in a recent study it was found that $45 \%$ of teachers stated that they never practice creative thinking, while $70 \%$ of the teachers stated that they only sometimes practice creative thinking skills in teaching [47].

Findings centred on this evidence based rely on the assumption that the issue of teaching and learning has emerged owing to the inadequate growth in professionalism and competence among teachers [5]. Hence, teachers need support to increase their capability to guide students' design thinking [48]. Chai, et al. [6] recommended that the further studies need to be conducted for in-service teachers to form teachers' awareness and competencies related to DT Mindset. Previous studies, have showed that teachers are still unclear about DT Mindset and how it could be applied in the classroom [29], [49], [50].

\section{CONCLUSION}

This concept paper makes a link of expertise to instructional planning and to the professional advancement of teachers in addressing the needs of education 4.0. While several studies have been undertaken on 21st-century education, this concept paper aims to fill the gap, to the benefit of academician and researchers in the context of education 4.0. Exposure to DT, DT Mindset and education 4.0 may improve students' success by developing creativity and innovation and thus improving the core skills required for the Industrial Revolution 4.0. This concept paper is intended to be a reference for teachers in Malaysia in instilling DT Mindset to develop creativity and innovation among students as per the requirements of education 4.0. The hope is that the paper will encourage understanding and awareness to all the teachers and 
those who are interested in creative thinking and innovation and encouraging students to describe their thoughts competence.

\section{ACKNOWLEDGEMENTS}

The authors would like to express our sincerest gratitude to the Scholarship and Financing Division, the Ministry of Education Malaysia, for the financial support.

\section{REFERENCES}

[1] World Economic Forum, The future of jobs report 2018: Insight Report - Centre for the New Economy and Society. Geneva, 2018.

[2] T. O. Kowang, et al., "Industry 4.0 competencies among lecturers of higher learning institution in Malaysia," International Journal of Evaluation and Research in Education (IJERE), vol. 9, no. 2, pp. 303-310, 2020.

[3] S. A. Garba, Y. Byabazaire, and A. H. Busthami, "Toward The Use o f 21 st century Teaching-Learning Approaches: The Trend Of Development In Malaysian Schools Within The Context Of Asia Pacific," International Journal of Emerging Technologies in Learning, vol. 10, no. 4, pp.72-79, 2015 .

[4] A. A. Shahroom, N. Hussin, "Industrial revolution 4.0 and education," International Journal of Academic Research in Business and Social Sciences, vol. 8, no. 9, pp. 314-319, Sep. 2018.

[5] R. M. Ellahi, M. U. Khan, and A. Shah, "Redesigning Curriculum in line with Industry 4.0," Procedia computer science, vol. 1, no. 151, pp. 699-708, Jan. 2019.

[6] C. S. Chai, J. H. L. Koh, U. Natarajan, P. S. Tsai, M. Ramli, and A. Widodo, "Surveying Indonesian Teachers' Design Belief and TPACK for 21st Century Oriented Learning," Proceedings of the 25th International Conference on Computers in Education, 2017, pp. 1001-1006.

[7] J. H. L Koh, C. S. Chai, and W. L. Lim, "Teacher professional development for TPACK-21CL: Effects on teacher ICT integration and student outcomes," J. Educ. Comput. Res., vol. 55, no. 2, pp. 172-196, 2017.

[8] D. Silva, M. Sobrinho, and N. Valentim, "TAEP4.0: Teacher Assistance Educational Process to Promote 21st Century Skills in the Context of Education 4.0," CSEDU 2020 International Conference on Computer Supported Education, vol. 1, 2020, pp. 249-259.

[9] A. Abdul Ghani, R. Che Hashim, and Y. MdYusoff, "The employability skills of Malaysian university students," Int J Mod Trends Soc Sci., vol. 1, no. 3, pp. 1-14, 2018.

[10] R. Jamaludin, E. McKay, and S. Ledger, "Are we ready for Education 4.0 within ASEAN higher education institutions? Thriving for knowledge, industry and humanity in a dynamic higher education ecosystem?" Journal of Applied Research in Higher Education, vol. 12, no. 5, pp. 1161-1173, 2020.

[11] N. Azid, R. Hasan, N. F. Nazarudin, and R. Md-Ali, "Embracing Industrial Revolution 4.0: The Effect of Using Web 2.0 Tools on Primary Schools Students' Mathematics Achievement (Fraction)," International Journal of Instruction, vol. 13, no. 3, pp. 711-728, Jul. 2020.

[12] H. Shafie, F. A. Majid, and I. S. Ismail, "Technological Pedagogical Content Knowledge (TPACK) in Teaching 21st Century Skills in the 21st Century Classroom," Asian Journal of University Education, vol. 15, no. 3, pp. 24-33, Dec. 2019.

[13] D. Dillon, Y. Chang, A. Rondeau, and J. Kim, "Teacher educator technology integration initiative: Addressing the technology preparation gap," Journal of Technology and Teacher Education. vol. 27, no. 4, pp. 527-554, 2019.

[14] O. Simsek and T. Yazar, "Examining the Self-Efficacy of Prospective Teachers in Technology Integration According to their Subject Areas: The Case of Turkey," Contemporary Educational Technology, vol. 10. no. 3, pp. 289-308, Jul. 2019.

[15] B. Robandi, E. Kurniati, and R. P. Sari, "Pedagogy in the Era of Industrial Revolution 4.0," 8th UPI-UPSI International Conference 2018 (UPI-UPSI 2018), Atlantis Press, Apr. 2019.

[16] W. Brenner, F. Uebernickel, and T. Abrell, "Design thinking as mindset, process, and toolbox," in W. Brenner, F. Uebernickel, Eds., Design Thinking for Innovation. Cham. Springer, 2016, pp. 3-21.

[17] D. Henriksen, C. Richardson, and R. Mehta, "Design thinking: A creative approach to educational problems of practice," Thinking skills and Creativity, vol. 26, pp.140-153, Dec. 2017

[18] M. Çetin and H. Ö. Demircan, "Empowering technology and engineering for STEM education through programming robots: a systematic literature review," Early Child Development and Care, vol. 190, no. 9, pp.1-13, 2018.

[19] S. Masapanta-Carrión and JÁ Velázquez-Iturbide, "A systematic review of the use of Bloom's taxonomy in Computer Science education," Proceedings of the 49th Acm Technical Symposium on Computer Science Education, Feb 2018, pp. 441-446,

[20] S. Y. Lye and J. H. Koh, "Review on teaching and learning of computational thinking through programming: What is next for K-12?" Computers in Human Behavior, vol. 41, pp. 51-61, Dec. 2014.

[21] R. Razzouk and V. Shute, "What is design thinking and why is it important?" Review of Educational Research, vol. 82, no. 3, pp. 330-348, Sep. 2012.

[22] J. H. L. Koh, C. S. Chai, W. Benjamin, and H.Y. Hong, "Technological pedagogical content knowledge (TPACK) and design thinking: A framework to support ICT lesson design for 21st century learning," The Asia-Pacific Education Researcher, vol. 24, pp. 535-543, Sep. 2015. 
[23] A. Crane, "Exploring Best Practices for Implementing Design Thinking Processes in K12 Education," Dissertation, University of Kansas, 2018.

[24] A. Scheer, C. Noweski, and C. Meinel, "Transforming constructivist learning into action: Design thinking in education," Design and Technology Education: An International Journal, vol. 17, no. 3, pp. 8-19, Oct. 2012.

[25] L. Lin, R. Shadiev, W. Y. Hwang, and S. Shen, "From Knowledge and Skills to Digital works: An Application of Design Thinking in the Information Technology Course," Thinking Skills and Creativity, vol. 36, Jun. 2020, doi: $10.1016 / j . t s c .2020 .100646$.

[26] G. Charosky, L. Leveratto, L. Hassi, K. Papageorgiou, J. Ramos-Castro, and R. Bragós, "Challenge based education: an approach to innovation through multidisciplinary teams of students using Design Thinking," 2018 XIII Technologies Applied to Electronics Teaching Conference (TAEE), Jun. 2018.

[27] M. Carroll, "Stretch, dream, and do-a 21st century design thinking \& STEM journey," Journal of Research in STEM Education, vol. 1, no. 1, pp. 59-70, 2015.

[28] I. Rauth, E. Köppen, B. Jobst, and C. Meinel, "Design Thinking: An Educational Model towards Creative Confidence," DS 66-2: Proceedings of the 1st international conference on design creativity (ICDC 2010), 2010.

[29] R. Lor, "Design Thinking in Education: A Critical Review of Literature," Asian Conference on Education and Psychology, Bangkok, Thailand, 2017, pp. 36-68.

[30] T. Brown, and D. F. Kuratko, "The impact of design and innovation on the future of education," Psychology of Aesthetics, Creativity, and the Arts, vol. 9, no. 2, pp. 147-151, May 2015.

[31] T. Brown, "Design thinking," Harvard Business Review, Jun. 2008.

[32] O. Serrat, "Design Thinking," In Knowledge Solutions. Springer, Singapore, 2017, doi: 10.1007/978-981-10-09839_18.

[33] L. Carlgren, I. Rauth, and M. Elmquist M, "Framing design thinking: The concept in idea and enactment," Creativity and Innovation Management, vol. 25, no. 1, pp. 38-57, Mar. 2016.

[34] Ministry of Education Malaysia (MoE), 2018 Annual Repot: MEB 2013-2025. Ministry of Education Malaysia, 2018.

[35] M. Carroll, S. Goldman, L. Britos, J. H. L. Koh, A. Royalty, and M. Hornstein, "Destination, imagination and the fires within: Design thinking in a middle school classroom," International Journal of Art \& Design Education, vol. 29, no. 1, pp. 37-53, Feb. 2010.

[36] L. Cohen, L. Manion, and K. Morrison, Research Methods in Education, 6th ed. Routledge, 2007.

[37] A. A. Hussin, "Education 4.0 made simple: Ideas for teaching," International Journal of Education and Literacy Studies, vol. 6, no. 3, pp. 92-98, Jul. 2018.

[38] J. C. Tu, L. X. Liu, and K.Y Wu, "Study on the learning effectiveness of Stanford design thinking in integrated design education," Sustainability, vol. 10, no. 8, pp. 26-49, Aug. 2018.

[39] N. Wright and C. Wrigley, "Broadening design-led education horizons: Conceptual insights and future research directions," International Journal of Technology and Design Education, vol. 29, no. 1, pp. 1-23, Jan. 2019.

[40] F. K. Thang and J. H. Koh, "Deepening and transferring twenty-first century learning through a lower secondary Integrated Science module," Learning: Research and Practice, vol. 3, no. 2, pp. 148-162, Jul. 2017.

[41] N. Azid and R. Md. Ali, "The effect of the successful intelligence interactive module on Universiti Utara Malaysia students' analytical, creative and practical thinking skills," South African Journal of Education, vol. 40, no. 3, pp. 1-11, Sep. 2020.

[42] A. M. Sharif and K. M. San, The Invention Curriculum: A Malaysian Experience. Innodata Monographs 11. International Bureau of Education, Geneva (Switzerland), 2001.

[43] A. F. Harun, J. Ismail, H. Y. Shiang,N. L. M. Noor, H. Baharin, and S. I. Suliman, "An exploratory study in conceptualizing user view on digital taste using design thinking," Indonesian Journal Electrical Engeneering Computer Science (IJEECS), vol. 17, no. 1, pp. 379-388, Jan. 2020.

[44] S. M. Shah and Z. M. Noor, "Integrating design thinking in distributed leadership as a decision-making process among 21st century secondary school principals in Malaysia," Journal of Teaching and Education, vol. 5, no. 1, pp. 385-394, Jun. 2016.

[45] M. Habibi, J. Jumadi, S. Gummah, S. Ahzan, and DS. Prasetya, "Project brief effects on creative thinking skills among low-ability pre-service physics teachers," International Journal of Evaluation and Research in Education (IJERE), vol. 9, no. 2, pp. 415-420, 2020.

[46] A.H. Mohd Adnan, R. Abd Karim, M. Haniff Mohd Tahir, N. N Mustafa Kamal, and A. Muhyiddin Yusof, "Education 4.0 Technologies, Industry 4.0 Skills and the Teaching of English in Malaysian Tertiary Education," Arab World English Jurnoul, vol. 10, no. 4, pp. 330-343, 2019.

[47] N. Mat Noh, S. Halili, and S. Siraj, "Learning Constraint Factor Analysis Based on Forms of Design in Teachers Based on the Fuzzy Delphi Method," (in Malay), Jurnal Kurikulum Pengajaran Asia Pasifik, vol. 8, no. 1, pp. 33-42, 2020. [Online]. Available: https://juku.um.edu.my/article/view/22200.

[48] N. Wright, E. Miller, L. Dawes, and C. Wrigley, "Beyond 'chalk and talk': educator perspectives on design immersion programs for rural and regional schools," International Journal of Technology and Design Education, vol, 30, no. 1, pp. 35-65, Mar. 2020.

[49] L. Carlgren, M. Elmquist, and I. Rauth, "Design thinking: Exploring values and effects from an innovation capability perspective," The Design Journal, vol. 17. no. 3, pp. 403-423, Sep. 2014.

[50] J. Schweitzer, L. Groeger, and L. Sobel, "The design thinking mindset: An assessment of what we know and what we see in practice," Journal of Design, Business \& Society, vol. 2, no. 1, pp. 71-94, Mar. 2016. 